\title{
KINETICS AND MECHANISM OF OXIDATION OF SUCROSE BY N-BROMONICOTINAMIDE NBN)
}

\author{
L. Pushpalatha
}

\author{
Postgraduate and Research Department of Chemistry, \\ National College, Trichy - 620 001, Tamil nadu, India. \\ Correspondent Fax No.: 91-0431-2431043 \\ E-mail address: lathaa_ramesh@yahoo.com
}

Keywords: Sucrose, N-Bromonicotinamide, oxidation, mechanism

\begin{abstract}
Kinetics study of oxidation of sucrose, by aqueous alkaline solution of NBromonicotinamide (NBN) has been carried out in the temperature range 308-323K. The reaction exhibits first order in $[\mathrm{NaOH}]$ and [Sucrose] and zero order about oxidant. Addition of nicotinamide (NA) has no effect. Increase in ionic strength of the medium does not change the rate. Effect of temperature on the rate of oxidation has been followed to show the validity of Arrehenius equation and various activation parameters have been computed. The stoichiometry of the reaction was found to be 1:1. 1,2-enediol is found to be the reactive intermediate. Arabinonic acid, glycolic acid and formic acid are the products of oxidation.
\end{abstract}

\section{INTRODUCTION}

Carbohydrates are biologically important substrates. The oxidation of sugars, especially the mono and disaccharides has been the subject of extensive research. Their oxidation can provide new compounds and materials with interesting physicochemical properties.

Sucrose and starch are readily amenable to chemical and biochemical modifications giving a range of compounds presently derived through petrochemical routes, as well as new derivatives of potential commercial significance. Sucrose is obtained from two sources, in the tropics from sugar cane and in the temperate zone from sugar beet. The production in all forms exceeds ninety six million tonnes per year. Considering the current low raw sugar prices, $£ 160$ per tonne on the world market, and the fact that production exceeds consumption by over five million tonnes, it is logical that other uses of sucrose are found.

H. K. Okoro [1] and E. O. Odebunmi reported the kinetics and mechanism of oxidation of sugar and sugar alcohols by potassium permanganate.

E.O. Odebunmi and S.O. Owalude [2] investigated the kinetics and mechanism of oxidation of some simple reducing sugars by permanganate ion in alkaline medium. E.O. Odebunmi [3] followed the kinetics of oxidation of fructose, sucrose and maltose by potassium permanganate in $\mathrm{NaHCO}_{3} / \mathrm{NaOH}$ buffer and iridium(IV) complex in sodium acetate/acetic acid buffer. Kinetics and mechanism of the oxidation of disaccharides by $\mathrm{Cr}(\mathrm{VI})$ was reported by Viviana Roldán [4].

N-halo reagents like N-halo derivatives of amines, amides, imides, urea, saccharins, sulfonamides, sulfonimides are widely used in organic synthesis.

Scant reports are available for oxidation of sugars by haloamides[5]. NBN is chosen for its versatility based on our earlier study on the oxidation of amino acids by $\mathrm{NBN}[6]$ in aqueous acetic acid medium.

In our continuing efforts to exploit NBN as oxidant, the present study describes the kinetics of oxidation of sucrose in aqueous alkaline medium. 


\section{EXPERIMENTAL}

\subsection{Materials}

N-Bromonicotinamide (NBN) was prepared by the reported method [7]. Standard solution of NBN (m.p. $210^{\circ} \mathrm{C}$ ) was prepared afresh in water and its purity was checked iodometrically. The standard solution of sucrose (Aldrich) was always prepared afresh in double distilled water. The other chemicals used were sodium hydroxide, sodium perchlorate, mercuric acetate etc. All chemicals used were of A.R. grade. Mercuric acetate was added to suppress the formation of free bromine which otherwise would have vitiated the results. Mercuric acetate did not interfere with the results[8]. Ionic strength of the medium was kept at $0.1 \mathrm{~mol} \mathrm{dm}^{-3}$ by employing concentrated aqueous solution of sodium perchlorate (Merck).

\subsection{Kinetic measurements}

The solution of sucrose and oxidant were kept in black coated bottles separately. These solutions were kept in the thermostat to attain the thermostatic temperature. The appropriate quantity of oxidant was added to the substrate containing other reagents and the reaction bottle was shaken well. The reaction was followed potentiometrically by setting up a cell made up of the reaction mixture into which the platinum electrode and reference electrode (SCE) were dipped. The e.m.f of the cell was measured periodically using a Equip-Tronics (EQ-DGD) potentiometer. Different studies such as variation of sucrose, oxidant(NBN), sodium hydroxide, sodium perchlorate, nicotinamide and temperature were carried out. The reaction was carried out under pseudo-first order condition ([sucrose] $>>[\mathrm{NBN}]$ ). The pseudo-first order rate constants computed from the linear $\left(r^{2}>0.9990\right)$ plots of $\log \left(E_{t}-E_{\infty}\right)$ against time. Duplicate kinetic runs showed that the rate constants were reproducible within $\pm 3 \%$. The course of the reaction was studied for more than two half-lives.

\subsection{Stoichiometry}

N-Bromonicotinamide was taken in large excess as compared to sucrose in different ratios. Reaction mixture containing sucrose, sodium hydroxide and N-bromonicotinamide (in excess) were equilibrated for 42 hours at room temperature $\left(\sim 30^{\circ} \mathrm{C}\right)$. After the reaction was complete, the excess of NBN was determined iodometrically and indicated 1:1 stoichiometry. The overall stoichiometry of the oxidation reaction may be represented as

$\mathrm{C}_{12} \mathrm{H}_{22} \mathrm{O}_{11}+\mathrm{NBN}+\mathrm{H}_{2} \mathrm{O}$

Sucrose

\section{$\mathrm{CH}_{2} \mathrm{OH}(\mathrm{COOH})+\mathrm{C}_{4} \mathrm{H}_{9} \mathrm{O}_{4}(\mathrm{COOH})+$}

Glycollic acid Arabiononic acid

$5 \mathrm{HCOOH}+\mathrm{Br}^{-}+\mathrm{NA}$

Formic acid

\subsection{Product Analysis}

In a typical experiment, a mixture of freshly prepared sucrose $\left(1 \mathrm{~mol} \mathrm{dm}^{-3}\right)$ and NBN $(1.5 \mathrm{~g}$, $0.2 \mathrm{~mol} \mathrm{dm}^{-3}$ ) was made up to $50 \mathrm{ml}$ with water. The mixture was allowed to stand for 12 hours in the dark to ensure completion of the reaction. The products of oxidation were arabinonic acid, formic acid and glycollic acid. Nicotinamide was the by-product. The products were identified by spot test analysis[9]. The products were also identified by the following method. A little of the product was added to $1 \mathrm{ml}$ of 5\% sodium bicarbonate solution. Evolution of carbon dioxide with effervescence indicated the presence of acidic group in the compound. Evidence for the formation of an enediol is furnished by observed ability of alkaline solution of carbohydrates to decolorize solution of 2,6-dichlorophenolindophenol. 


\section{RESULTS}

The kinetic results for the oxidation of sucrose by N-Bromonicotinamide (NBN) can be summarized as follows. The kinetic studies were carried out under pseudo-first order conditions with [sucrose] $>$ [NBN].

\subsection{Effect of varying [oxidant]}

The constancy of pseudo-first order rate constant at different [NBN] at constant [sucrose] indicates the reaction exhibits zero order about the oxidant (Table 1).

Table 1- Effect of variation of [NBN] on reaction rate

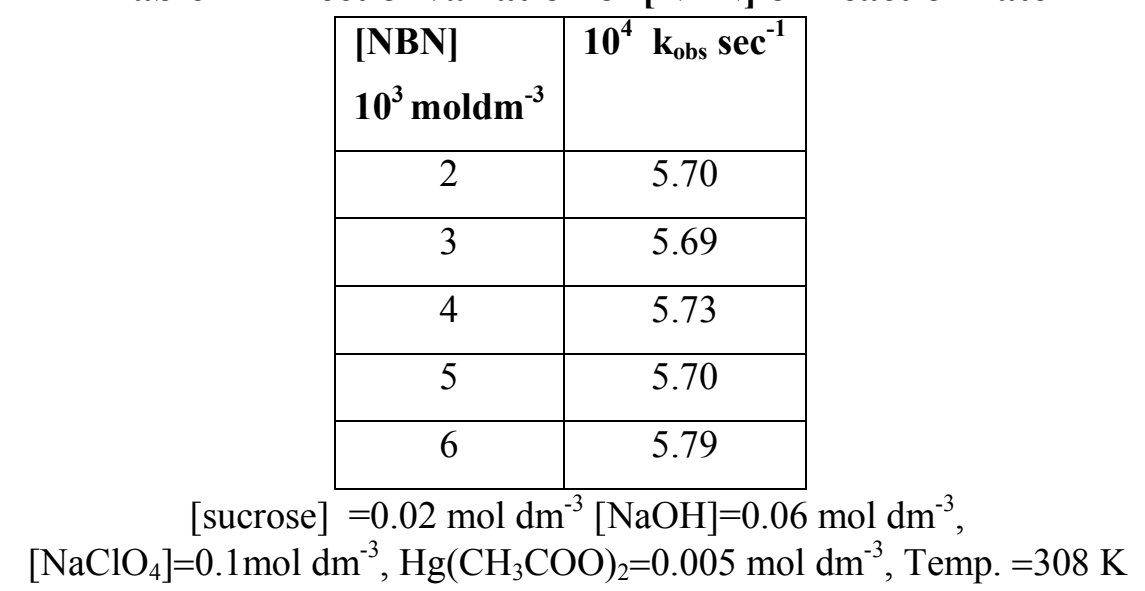

\subsection{Effect of varying [sucrose]}

At constant $\left[\mathrm{OH}^{-}\right],[\mathrm{NBN}]$, the plot of $\log \left(\mathrm{E}_{t}-\mathrm{E} \infty\right.$ ) (where $\mathrm{E}_{t}$ is the e.m.f. of the cell at time $t$ and $\mathrm{E}_{\infty}$, the corresponding value at the completion of the reaction) Vs time is linear, indicating a first order dependence of rate on [sucrose]. The rate constant increases in direct proportionality with the increase in the concentration of sucrose, proving the reaction is of first order in [sucrose]. (Table 2).

Table 2- Effect of variation of [Sucrose] on reaction rate

\begin{tabular}{|c|c|}
\hline $\begin{array}{l}\text { [Sucrose] } \\
\mathbf{1 0}^{\mathbf{2}} \mathbf{~ m o l d m}^{-3}\end{array}$ & $\mathbf{1 0}^{\mathbf{4}} \mathbf{k}_{\text {obs }} \mathbf{~ s e c}^{-1}$ \\
\hline 2.0 & 5.70 \\
\hline 3.0 & 6.43 \\
\hline 4.0 & 7.11 \\
\hline 5.0 & 7.75 \\
\hline 6.0 & 8.35 \\
\hline
\end{tabular}

$[\mathrm{NBN}]=0.002 \mathrm{~mol} \mathrm{dm}^{-3}[\mathrm{NaOH}]=0.06 \mathrm{~mol} \mathrm{dm}^{-3}$,

$\left[\mathrm{NaClO}_{4}\right]=0.1 \mathrm{~mol} \mathrm{dm}^{-3}, \mathrm{Hg}\left(\mathrm{CH}_{3} \mathrm{COO}\right)_{2}=0.005 \mathrm{~mol} \mathrm{dm}^{-3}$, Temp. $=308 \mathrm{~K}$

\subsection{Effect of varying $\left[\mathrm{OH}^{-}\right]$}

A scrutiny of table 3 shows that the rate increases proportionally with the increase in $[\mathrm{NaOH}]$. The plot of $\log \mathrm{k}_{\mathrm{obs}}$ versus $\log \left[\mathrm{OH}^{-}\right]$was linear with a unit slope indicating first order dependence on [sodium hydroxide] (Table 3). 
Table 3- Effect of variation of $\left[\mathrm{OH}^{-}\right]$on reaction rate

\begin{tabular}{|c|c|}
\hline $\begin{array}{c}{[\mathbf{N a O H}]} \\
\mathbf{1 0}^{2} \mathbf{~ m o l d m}^{-3}\end{array}$ & $\mathbf{1 0}^{\mathbf{4}} \mathbf{k}_{\mathbf{o b s}} \mathbf{s e c}^{-1}$ \\
\hline 6 & 5.70 \\
\hline 8 & 6.67 \\
\hline 10 & 7.56 \\
\hline 12 & 8.42 \\
\hline 15 & 9.52 \\
\hline
\end{tabular}

$$
\begin{gathered}
{[\mathrm{NBN}]=0.002 \mathrm{~mol} \mathrm{dm}^{-3}[\text { sucrose }]=0.02 \mathrm{~mol} \mathrm{dm}^{-3},} \\
{\left[\mathrm{NaClO}_{4}\right]=0.1 \mathrm{~mol} \mathrm{dm}{ }^{-3}, \mathrm{Hg}\left(\mathrm{CH}_{3} \mathrm{COO}\right)_{2}=0.005 \mathrm{~mol} \mathrm{dm}^{-3}, \text { Temp. }=308 \mathrm{~K}}
\end{gathered}
$$

\subsection{Effect of addition of nicotinamide}

The effect of one of the product of the reaction has been studied by adding various concentrations of nicotinamide, keeping concentration of sucrose, NBN constant. There is no significant change in the rate of reaction.

\subsection{Effect of ionic strength}

The effect of ionic strength was studied by carrying out investigations in the presence of different amounts of sodium perchlorate. No appreciable salt effect was detected.

\subsection{Effect of added salts}

Added salts like $\mathrm{BaCl}_{2}, \mathrm{KCl}, \mathrm{Na}_{2} \mathrm{SO}_{4}$ and $\mathrm{K}_{2} \mathrm{SO}_{4}$ do not have any effect on the rate.

\subsection{Test for free radicals}

The possibility of free radical intervention in the NBN oxidation reaction was tested by the following procedure. The reaction mixture containing acrylonitrile scavenger was kept for 24hours in an inert atmosphere and then diluted. On dilution, formation of precipitate was not observed indicating the absence of free radical intervention in the reaction.

\subsection{Effect of temperature}

Increase in temperature increases the rate of oxidation and plot of $\log \mathrm{k}_{\mathrm{obs}} \mathrm{Vs}$ reciprocal of temperature is linear. The oxidation of sucrose by NBN was studied at different temperatures (308K to $323 \mathrm{~K}$ ) (Table 4 ) and the activation parameters were evaluated (Table 5) 
Table 4- Effect of Temperature on reaction rate

\begin{tabular}{|c|c|}
\hline $\begin{array}{c}\text { Temperature } \\
\mathbf{K}\end{array}$ & $\mathbf{1 0}^{\mathbf{5}} \mathbf{k}_{\text {obs }} \mathbf{s e c}^{-\mathbf{1}}$ \\
\hline 308 & 5.70 \\
\hline 313 & 7.26 \\
\hline 318 & 9.07 \\
\hline 323 & 11.28 \\
\hline 328 & 13.66 \\
\hline
\end{tabular}

[sucrose $]=0.02 \mathrm{~mol} \mathrm{dm}^{-3}[\mathrm{NaOH}]=0.06 \mathrm{~mol} \mathrm{dm}^{-3}$, $[\mathrm{NBN}]=0.002 \mathrm{~mol} \mathrm{dm}^{-3}\left[\mathrm{NaClO}_{4}\right]=0.1 \mathrm{~mol} \mathrm{dm}^{-3}$,

$\mathrm{Hg}\left(\mathrm{CH}_{3} \mathrm{COO}\right)_{2}=0.005 \mathrm{~mol} \mathrm{dm}^{-3}$

Table 5- Activation Parameters

\begin{tabular}{|c|c|c|c|c|}
\hline Substrate & $\mathbf{E}_{\mathbf{a}} \mathbf{~ k J m o l}^{\mathbf{1}}$ & $\Delta \mathbf{H}^{\#} \mathbf{k J m o l}^{\mathbf{1}}$ & $\Delta \mathbf{S}^{\#} \mathbf{J ~ K}^{\mathbf{- 1}} \mathbf{m o l}^{\mathbf{1}}$ & $\Delta \mathbf{G}^{\#} \mathbf{k J m o l}$ \\
\hline Sucrose & 18.48 & 15.92 & -183.6 & 72.47 \\
\hline
\end{tabular}

\section{DISCUSSION}

The possible oxidizing species in alkaline medium are $\mathrm{NBNBr}, \mathrm{Br}_{2}$ and $\mathrm{HOBr}$. The observed zero order dependence of the reaction rate on NBN rules out $\mathrm{NBNBr}$ and molecular bromine as the reactive oxidizing species. Addition of nicotinamide having no effect on the rate indicates that $\mathrm{HOBr}$ may not be the oxidizing species. $\mathrm{H}_{2} \mathrm{OBr}$ may be discarded because of negligible effect of addition of nicotinamide on reaction rate. A careful study of the kinetics of oxidation of sucrose shows that the rate expression is of the form

$$
-\frac{d[N B N]}{d t}=\mathrm{k}[\text { sucrose }]\left[\mathrm{OH}^{-}\right]
$$

which implies that the rate of reaction is independent of the concentration of [NBN], while the reaction is of first order both with respect to sucrose as well as alkali. In cases where the concentration of sucrose as well as alkali is large as compared to the concentration of [NBN], the rate expression becomes

$$
\frac{d[N B N]}{d t}=\mathrm{k}_{\mathrm{s}}=\Delta \chi / \Delta \mathrm{t}
$$

Where $\mathrm{k}_{\mathrm{s}}=\mathrm{k}[$ sucrose $]\left[\mathrm{OH}^{-}\right]$

\subsection{Mechanism}

On the basis of the above experimental results, it appears that the first slow step involves a reaction between hydroxide ion and sucrose, leading to the formation of an intermediate reactive form:

$$
\begin{aligned}
& \mathrm{S}+\mathrm{HO}^{-} \stackrel{\mathbf{k}_{\mathbf{1}}}{\underset{\mathrm{K}_{-1}}{\mathrm{D}}} \quad \begin{array}{l}
\mathrm{H}-\mathrm{C}(\mathrm{OH})=\mathrm{CR}(\mathrm{OH})+\mathrm{H}_{2} \mathrm{O} \quad \text { (I step) } \\
1,2 \text { Enediol }(\mathrm{E})
\end{array} \\
& \text { (slow) } \mathrm{R}-\mathrm{C}_{10} \mathrm{H}_{19} \mathrm{O}_{9}
\end{aligned}
$$


where S represents the sugar. The fact that this step is slow explains how the order of the reaction is unity with respect to reducing sugar. Further, this intermediate reactive form, which is called, 1,2 enediol, is subsequently oxidized by NBN to form arabinonic acid, formic acid, glycollic acid and nicotinamide.

$$
\text { en }(\mathrm{E})+\mathrm{NBN} \underset{\text { fast }}{\stackrel{\mathrm{k}_{2}}{\longrightarrow}} \text { products }+\mathrm{NA} \quad \text { (II step) }
$$

\{Products - arabinonic acid, formic acid, glycollic acid \}

where " en " represents 1,2 enediol. The fact that the second step is fast explains the zero order of the reaction with respect to [NBN].

It may be pointed out that in the present study, oxidation by bromine was completely suppressed as the oxidative studies were carried out in presence of mercuric acetate which combines with bromide ions formed in the reaction[8]. Thus kinetics of only NBN oxidation was followed.

The involvement of substrate molecule in the rate-determining step leads to different values of $\mathrm{k}_{\mathrm{obs}}$ for different initial concentrations of sucrose.

\section{CONCLUSION}

The reaction rates are enhanced by increase in [substrate], [alkali] and temperature. Addition of nicotinamide has no effect on the rate. 1,2-Enediol form of sugar is the reactive intermediate leading to products. The oxidation products are arabinonic acid, glycolic acid and formic acid. Suitable mechanism in agreement with experimental observations was proposed and the rate law was derived.

\section{ACKNOWLEDGEMENTS}

The author gratefully acknowledges her husband, A. Ramesh for the physical and moral support.

\section{References}

[1] Okoro H. K., Odebunmi E. O., International Journal of Physical Sciences 4 (9) (2009) 471.

[2] Odebunmi E. O., Owalude S.O., J. Iran. Chem. Soc. 5( 4) (2008) 623.

[3] Odebunmi E. O., Iwarere S.A., Owalude S.O., International Jour. Chem. 16(3) (2006) 167.

[4] Viviana Roldán, Juan Carlos González, Mabel Santoro, Silvia García, Nieves Casado, Silvina Olivera, Juan Carlos Boggio, Juan Manuel Salas-Peregrin, Sandra Signorella, Luis F. Sala Can. J. Chem. 80 (2002) 1676.

[5] (a) Pushpalatha L., Oxid. Commun., 36(4)(2013) 901.

(b) Pushpalatha L., AFINIDAD 68 (2011) 551.

(c) Pushpalatha L., Oxid. Commun., 37(1) (2014) 121.

(d) Pushpalatha L., Oxid. Commun., 37(1) (2014) 129.

(e) Pushpalatha L., Oxid. Commun., 37(1) (2014) 138.

[6] (a) Pushpalatha L ., Vivekanandan K., J. Indian Chem. Soc., 86 (2009) 475.

(b) Pushpalatha L., Vivekanandan K., Oxid. Commun., 32(1) (2009) 85-93. 
(c) Pushpalatha L., Vivekanandan K., Oxid. Commun., 31(3) (2008) 598.

(d) Pushpalatha L., Vivekanandan K., .J. Indian Chem. Soc., 85 (2008) 1027.

(e) Pushpalatha L., Vivekanandan K., Oxid. Commun., 33(4) (2010) 851.

(f) Pushpalatha L., Oxid. Commun., 36(4)(2013) 938.

(g) Pushpalatha L., Oxid. Commun., 36(4)(2013) 901.

(h) Pushpalatha L., Vivekanandan K., Oxid. Commun., 36(4) (2013) 583.

(i) Pushpalatha L., Vivekanandan K., J. Indian Chem. Soc., 87 (2010) 1221.

[7] Hauser C.R., Renfrow Jr W.B., J. Am. Chem. Soc., 59 (1923) 121.

[8] Anupama Agarwal, Suman Mittal, Banerji K.K., Indian J. Chem., 26A, (1987) 339.

[9] F.Feigl: “ Spot Tests in Organic Analysis”, Elsevier, New York 325 (1966). 